\title{
The Effect of Interfacial Transition Zone Properties on the Elastic Properties of Cementitious Nanocomposite Materials
}

\author{
Ala G. Abu Taqa, ${ }^{1}$ Rashid K. Abu Al-Rub, ${ }^{2}$ Ahmed Senouci, ${ }^{3}$ \\ Nasser Al-Nuaimi, ${ }^{1}$ and Khaldoon A. Bani-Hani ${ }^{4}$ \\ ${ }^{1}$ Department of Civil and Architectural Engineering, Qatar University, P.O. Box 2713, Doha, Qatar \\ ${ }^{2}$ Institute Center for Energy, Mechanical and Materials Engineering Department, Masdar Institute of Science and Technology, \\ P.O. Box 54224, Abu Dhabi, UAE \\ ${ }^{3}$ Department of Construction Management, University of Houston, Houston, TX 77204-4020, USA \\ ${ }^{4}$ Department of Civil Engineering, Jordan University of Science and Technology, P.O. Box 3030, Irbid 22110, Jordan
}

Correspondence should be addressed to Ala G. Abu Taqa; aal104819@qu.edu.qa

Received 25 March 2015; Accepted 31 March 2015

Academic Editor: Stefano Bellucci

Copyright ( 2015 Ala G. Abu Taqa et al. This is an open access article distributed under the Creative Commons Attribution License, which permits unrestricted use, distribution, and reproduction in any medium, provided the original work is properly cited.

\begin{abstract}
A parametric study was conducted to explore the effect of the interfacial transition zone (ITZ or interphase) on the overall elastic modulus of the CNT-reinforced cement. The effect of the ITZ properties on the elastic modulus of the CNT-reinforced cement was investigated using a four-phase axisymmetric model consisting of a single CNT aligned at the center of composite unit cell, an interface, an ITZ (or interphase), and a cement matrix. The CNT and cement matrix were assumed fully elastic while the interface was modeled using a cohesive surface framework. The width and mechanical properties of the ITZ and the interface were found to affect significantly the elastic modulus and the behavior of the composite material.
\end{abstract}

\section{Introduction}

Due to their excellent physical, mechanical, thermal, and electrical properties, carbon nanotubes (CNTs) are able to produce composites with outstanding properties. For example, single walled CNTs have a modulus of elasticity of approximately $1 \mathrm{TPa}$ (i.e., slightly lower than that of diamond), a yield strength between 20 and $60 \mathrm{GPa}$, thermal conductivity almost two times that of diamond [1], and a carrying capacity 1000 times higher than copper [2]. Moreover, CNTs have a high fracture strain capacity (i.e., more than $10 \%$ elastic strain at yielding) and a low density.

The utilization of CNTs has attracted researchers in all scientific disciplines. For example, CNTs were used as sensors in human and medical science [3-8]. They were also utilized in food safety discipline for the determination of some chemicals in food samples which prevent the foodborne illnesses [9]. Moreover, CNTs have the capability of producing a new class of composites with upgraded qualities because of their high fracture strain capacity, low density, and elastic behavior under large strains [10-13].

Previous experimental results have showed marginal improvement in the properties of CNT-reinforced cementitious materials. On the other hand, several theoretical studies have predicted higher enhancement levels. The difference between the experimental and theoretical findings may be attributed to (1) a poor dispersion of carbon nanotubes, (2) a weak interfacial bonding between the matrix and the CNTs, and (3) an agglomeration and/or defect of CNTs.

The region surrounding the CNT has a significant influence on the mechanical properties of the bulk composite. Thus, the properties of this region need to be included in the modeling of CNT-reinforced cementitious materials. The region is characterized by an interfacial transition zone (ITZ or interphase) and an interface. The ITZ or interphase region is defined as the layer of finite thickness and distinct mechanical properties between the CNT/cement interface and the cement matrix. On the other hand, the interface 
is defined as the cohesive surface with zero thickness lying between the CNT and the interphase.

A limited number of experimental studies have been conducted to investigate the interfacial properties in CNTreinforced cementitious materials as compared to those performed on CNT/polymer composites [14]. If the friction after debonding is ignored, the interfacial properties mainly control the load transfer mechanism between the CNT and the cement matrix. However, Naaman et al. [15] reported interfacial shear strength values in the range from 1.4 MPa to 9.6 MPa between the steel fiber-reinforced concrete (SFRC) and cement-based matrices. On the other hand, Chan and Andrawes $[16,17]$ reported an effective shear strength value of 6.5 MPa between CNTs and the cement matrix using threepoint bending test results to calibrate the numerical model. They also used interfacial shear strength values between $5 \mathrm{MPa}$ and $20 \mathrm{MPa}$ in their parametric study.

The effect of the interphase, or ITZ, on the mechanical properties of CNT-reinforced cementitious materials is also significant. For example, it is widely accepted that the properties of the ITZ in concrete (without fibers) need to be considered for a better estimation of the overall mechanical properties. However, very little research has been done to characterize and provide quantitative measurements of the interphase. Interphase widths of less than $100 \mathrm{~nm}$ with quantitative mechanical measurements at each position have rarely been reported in the literature. This is due to the lack of experimental techniques that can measure the mechanical properties in nanoscale spatial resolution (Nair et al. [18]). The elastic modulus of the ITZ was usually assumed to be uniform and lower than that of the paste matrix by a constant factor [19]. Although there is not enough theoretical or experimental evidence to support this assumption, this factor was assumed to have a value between 0.2 and 0.8 [20]. Lutz et al. [21] assumed that the elastic properties within the ITZ vary smoothly as a power function. They found that the modulus of the ITZ is 30 to 50 percent lower than that of the bulk matrix. In some recent studies, attempts were made to determine the local mechanical properties of the ITZ using microindentation testing [22]. Moreover, nanoindentation testing is a relatively new approach to measure the interphase size and mechanical properties in the nanoscale. Mondal et al. [23] characterized the mechanical properties of the ITZ between the paste and the aggregate using nanoindentation. They found that the average modulus in the interfacial zone is from $70 \%$ to $85 \%$ of that of the cement matrix. They also showed that the modulus of cement paste increases with the distance away from the aggregate. This finding contradicted those reported by Zhu et al. [24] who used microindentation to study the ITZ between the paste and the steel bar. Zhu et al. [24] reported that the elastic modulus decreases within the ITZ, which extends from 10 to $30 \mu \mathrm{m}$ from the actual steel interface. Moving away from the ITZ region, the elastic modulus value increases and becomes roughly constant at distances greater than 40 to $50 \mu \mathrm{m}$.

Researchers have recently used Atomic Force Microscopy (AFM), nanoindentation, and nanoscratching to investigate the interphase in fiber/polymer composites. Williams et al. [25] estimated the thickness of the interphase in a carbon fiber/epoxy system to be $500 \mathrm{~nm}$ using a micro pull-out method. Vanlandingham et al. [26] estimated the thickness of the interphase in a copolymer to be $3 \mu \mathrm{m}$ using Atomic Force Microscopy (AFM) and nanoindentation techniques. Munz et al. [27] used scanning force microscopy (SFM) to assess the local mechanical properties of fiber-reinforced polymers assuming a single exponential decrease in the local stiffness along a radial line from the fiber to the polymer. They found that the characteristic decay lengths vary between 20 and $80 \mathrm{~nm}$. Mai et al. [28] reported that the interphase thickness in a glass fiber/epoxy composite is from 1 to $3 \mu \mathrm{m}$ using the Atomic Force Microscopy (AFM) technique. Bogetti et al. [29] reported the interphase in a carbon fiber/epoxy system to be $3 \mathrm{~nm}$. Downing et al. [30] used phase imaging AFM and nanoindentation to examine the interphase in a glass fiber-reinforced epoxy composite matrix. Their nanoindentation experiments indicated that the relatively stiff fiber might have caused a gradient in the elastic modulus across the interphase region. The elastic modulus within the ITZ approached the fiber elastic modulus at the interface and decreased by moving away from the fiber. The interphase was found to have a thickness from 2.4 to $2.9 \mu \mathrm{m}$ and to be independent of the fiber pretreatment and softer than the bulk phase. Hodzic et al. [31] also conducted nanoindentation and nanoscratching on polymer/glass composite systems to determine the interphase thickness. Nanoindentation and AFM have also been widely used to determine the fiber bias effect on the interphase in epoxy/fiber glass systems and epoxy/aluminum joints [32, 33]. Lee et al. [34] investigated the interphase properties of a natural fiber-composite using nanoindentation and finite element analysis. They showed that the interphase width was less than $1 \mu \mathrm{m}$. However, they could not estimate the exact mechanical properties of the interphase. They concluded that the nanoindents needed to be smaller than the ones they have used. Lee et al. [35] investigated the interfacial zone of a lyocell/polypropylene composite modified by maleated polypropylene (MAPP) and APS using Atomic Force Microscopy Phase Imaging (AFMPI). They reported that the ITZ width ranged from approximately $113 \mathrm{~nm}$ to $128 \mathrm{~nm}$ and $107 \mathrm{~nm}$ to $173 \mathrm{~nm}$ using MAPP and APS, respectively. They suggested that the chemical modification of fibers increased the width of the interfacial zone and promoted cross-linking reactions between the two coupling agents.

Nair et al. [18] evaluated the interphase of natural fiberreinforced polymer composites using Contact Resonance Force Microscopy (CR-FM). The nanoscale spatial resolution of CR-FM, combined with its ability to provide quantitative modulus images, allowed the investigation of the mechanical properties of interphases as narrow as $50 \mathrm{~nm}$. (Gu et al. [36]) used the dynamic nanomechanical mapping technique to investigate the characterization and dimension of the interphase in carbon fiber-reinforced polymer composites (CFRPs). The average interphase thicknesses were found to be from $118 \mathrm{~nm}$ to $163 \mathrm{~nm}$ for fiber diameters of $7 \mu \mathrm{m}$. Pakzad et al. [37] studied the gradient of nanomechanical properties in the interphase of cellulose nanocrystal composites (CNCs). They reported that the interphase thickness is higher for CNCs with larger diameter. Needleman et al. [38] investigated 
the effect of varying the interface strength on the composite stress-strain response and on debonding both with and without an interphase. In their work, the interphase was assumed to be stronger than the matrix and its elastic modulus was assumed to increase linearly within the interphase. They reported that while the presence of an interphase increased the composite stiffness, it caused debonding which ultimately reduced the composite stress carrying capacity.

Pakravan et al. [39] investigated the adhesion of polypropylene (PP) fibers to a cementitious matrix. They also studied the chemical bonding and mechanical interlocking between the PP fiber and the hardened cement paste. Scanning Electron Microscopy (SEM) analysis was used to study the fiber-cement matrix interfacial transition zone (ITZ). The results showed that the application of polymerpolymer adhesion theories in fiber-cement matrix systems was feasible. Wang et al. [40] investigated the characteristics of the elastic modulus profiles. They also investigated the fiber-matrix-aggregate interfacial zones in steel fiberreinforced mortars using nanoindentation and SEM. However, very limited research was reported in the literature to investigate the ITZ in CNT-reinforced cementitious materials at the nanoscale level. The new techniques that are used to investigate the properties of the ITZ in composites (such as nanoindentation and AFM) are not yet widely utilized in the nanocomposite cement. Recently, Da Silva et al. [41] evaluated the elastic properties of the high performance cementitious composites (HPCC) (without fibers) at different length scales. They used nanoindentation at the microscale level while they investigated the macroscale elastic moduli using the static and dynamic compressive strength tests. The nanoindentation results, obtained from a representative microlevel area by grid indentation with subsequent phase deconvolution, were inserted into a two-step analytical homogenization scheme to predict the overall macroscale elastic properties of the high performance cementitious composites (HPCC).

This study represents a portion of the work done by the authors to investigate the elasticity of nanocomposite cement paste. In this paper, a four-phase axisymmetric unit cell model has been developed for a single aligned CNT embedded in the cement matrix with appropriate boundary conditions. The model has been used to conduct a parametric study to explore the effect of the mechanical properties of the ITZ (or interphase) and those of the interface on the elastic response of CNT-reinforced cementitious materials. However, the fiber waviness and random distribution within the matrix are the main features that limit their effectiveness and may result in composite with mechanical properties lower than composite with aligned fibers. Another study should be directed towards investigating the effect of fiber waviness and distribution on the elastic modulus of the nanocomposite cement paste using $3 \mathrm{D}$ and axisymmetric models assuming different distributions of fibers (uniformly or randomly distributed straight and curved CNTs). A novel methodology should be followed to simulate the 3D random distribution using the axisymmetric models and compare the results. As the focus of this study is to investigate the effect of the properties of the ITZ on the overall elastic behavior
TABLE 1: Mechanical properties of the cement matrix and fibers.

\begin{tabular}{lccc}
\hline & \multicolumn{2}{c}{ Elastic modulus $(E)$} & \multirow{2}{*}{ Poisson's ratio $(\nu)$} \\
& $\mathrm{GPa}$ & $\mathrm{N} /(\mathrm{nm})^{2}$ & \\
\hline Cement matrix & 30 & $3 \times 10^{-8}$ & 0.20 \\
CNT & 1000 & $1 \times 10^{-6}$ & 0.35 \\
\hline
\end{tabular}

of the nanocomposite cement paste, the simple axisymmetric model with one CNT aligned at the center of the matrix is used in this study without considering the orientation and random distribution of the fibers. The effects of random distribution and waviness of CNTs on the elastic properties of the nanocomposite cement are presented in Abu Taqa et al. [42].

\section{Modeling and Assumptions}

An axisymmetric model has been developed to investigate the effect of ITZ on the overall elastic modulus of the CNTreinforced cement paste. Several models were found in the literature to simulate the behavior of CNTs as space frame [43], truss [44], shell [45], beam [46], or equivalent-continuum tube [47]. However, as the focus of this work is to investigate the effect of the properties of the ITZ on the overall elastic behavior rather than the local stresses, strength, and ductility, the CNTs were modeled as beams. The model did not capture the hollow nature of CNTs. Furthermore, the interlayer movement of the multiwalled nanotubes (MWNTs) was neglected. These simplified assumptions may be acceptable herein and will tremendously reduce computational effort. However, this work can be extended to incorporate the exact nature of CNTs to study the composite strength and local stresses. The behavior of the CNT, interphase, and cement matrix was assumed to be linearly elastic. On the other hand, the interface was modeled using a cohesive surface model neglecting the interfacial friction after debonding. The assumption of an elastic cement paste is acceptable because the study investigates the overall elastic modulus of the composite rather than its strength and ductility. The mechanical properties used for the cement matrix and the fiber are shown in Table 1.

2.1. Axisymmetric Model. The representative volume element (RVE) of the CNT-reinforced cement paste was first divided into unit cells having hexagonal cross section and containing a single carbon nanotube in its center. Then, the hexagonal cross section was replaced by an equivalent circular cross section to form an axisymmetric unit cell. In the study, the axisymmetric model consisted of four phases, namely, CNT, interface, interfacial transition zone (ITZ or interphase), and cement matrix as shown in Figure 1. The commercial finite element software Abaqus was used in the analysis. A 4-node bilinear axisymmetric quadrilateral element with reduced integration (CAX4R) was used to model the CNT, interphase, and cement matrix. On the other hand, the cohesive surface framework was used to model the interface. 


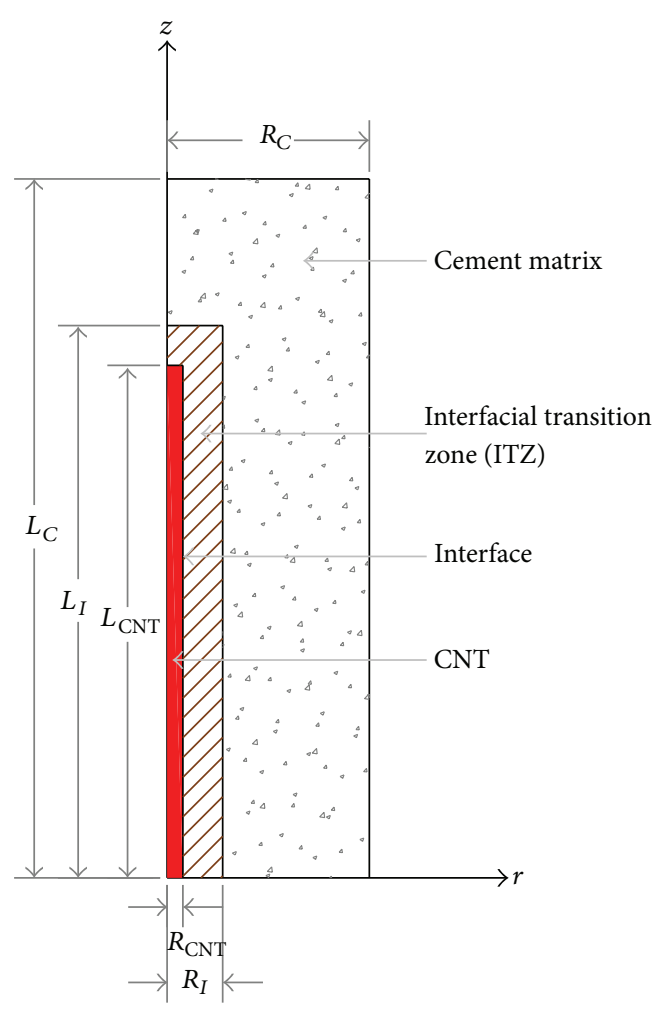

FIGURE 1: Four-phase axisymmetric model.

2.1.1. Geometry. The unit cell length was taken equal to $2 L_{C}=$ $1.5 \mu \mathrm{m}$. The length and diameter of the CNT were taken equal to $2 L_{\mathrm{CNT}}=1.1 \mu \mathrm{m}$ and $2 R_{\mathrm{CNT}}=10 \mathrm{~nm}$, respectively. The unit cell radius, $R_{C}$, was changed for each CNT volume fraction using the following equation:

$$
f_{\mathrm{CNT}}=\frac{R_{\mathrm{CNT}}^{2} L_{\mathrm{CNT}}}{R_{\mathrm{C}}^{2} L_{\mathrm{C}}},
$$

where the CNT is the volume fraction.

The distribution of the ITZ (or interphase) around the CNT was assumed to be uniform (i.e., $L_{I}-L_{\mathrm{CNT}}=R_{I}-$ $\left.R_{\mathrm{CNT}}\right)$. The length and radius of the interphase $\left(L_{I}, R_{I}\right)$ were calculated using the following equation:

$$
f_{I}=\frac{R_{I}^{2} L_{I}}{R_{C}^{2} L_{C}}-f_{\mathrm{CNT}},
$$

where the interphase is the volume fraction.

\subsubsection{Boundary Conditions}

(a) At $z=L_{C}$. The computations were carried out up to an axial strain equal to 0.0005 , which is equivalent to a tension displacement of $0.375 \mathrm{~nm}$. The range of computations was limited to this small strain value to guarantee that the CNT does not fully debond from the cement matrix even for small values of interfacial strengths. In order to set the time scale, achieve the convergence, and get more accurate stressstrain diagram in the elastic region, the displacement rate was applied at small time increments.

(b) At $r=R_{C}$. The boundary condition $u_{r}\left(R_{C}, z\right)=W$ was applied, where $W$ was determined from the condition $\sum r=$ 0 , where $\sum r$ is the average stress in the radial direction. The boundary condition was enforced by running the model first without applying any pressure at the boundary $r=R_{C}$. Then, the boundary was subjected to a pressure equal and opposite to the average radial stress at the boundary.

2.1.3. Meshing. Different mesh sizes were investigated to check the sensitivity of the analysis results to the meshing size. A $1 \mathrm{~nm} \times 1 \mathrm{~nm}$ mesh size generated a sufficient accuracy.

2.1.4. Interface. The cohesive surface framework used to describe the CNT/interphase interface was based on the traction-separation behavior, which allows for both normal and tangential separations. It can be modeled in Abaqus software as a cohesive interaction because (1) the interface thickness is very small (i.e., approaching zero) and (2) the overall behavior of the composite is investigated rather than the exact stresses within the interface. As the displacement across the cohesive interface increases, the interface traction first increases until it reaches a maximum and then decreases to zero, if the friction between the CNT and the matrix is ignored.

The available traction-separation model in Abaqus assumes an initial linear elastic behavior followed by the initiation and evolution of damage. Once a damage initiation criterion is met, a material damage can occur according to a specified damage evolution law.

The elastic behavior is written in terms of an elastic constitutive matrix that relates the nominal stresses to the nominal strains across the interface as follows:

$$
t=\left\{\begin{array}{l}
t_{N} \\
t_{T}
\end{array}\right\}=\left(\begin{array}{ll}
K_{N N} & K_{N T} \\
K_{N T} & K_{T T}
\end{array}\right)\left\{\begin{array}{c}
\varepsilon_{N} \\
\varepsilon_{T}
\end{array}\right\},
$$

where $t_{N}=$ normal stress/traction at the interface, $t_{T}=$ tangential stress/traction at the interface, $K_{N N}=$ normal stiffness of the interface, $K_{T T}=$ tangential stiffness of the interface, $K_{N T}=$ coupled stiffness of the interface, $\varepsilon_{N}=$ normal strain of the interface, and $\varepsilon_{T}=$ tangential strain of the interface.

If an uncoupled behavior between the normal and shear components is desired (as considered in the calculations here), $K_{N T}$ is set equal to zero. The nominal strains are the separations divided by the original thickness at each integration point. In Abaqus, the default value of the original constitutive thickness is 1.0 if the traction-separation response is specified. This ensures that the nominal strain is equal to the separation at the interface.

When the stresses and/or strains at the interface point satisfy the specified damage initiation criteria, the process of degradation of the response of that point begins. Several damage initiation criteria are available in Abaqus. However, the one used in this work depends on the maximum nominal 
stress criteria which assumes that the damage initiates when the maximum nominal stress/traction ratio reaches a value of one. This criterion can be represented using the following equation:

$$
\operatorname{Max}\left\{\frac{\left\langle t_{N}\right\rangle}{t_{N}^{o}}, \frac{t_{T}}{t_{T}^{o}}\right\}=1,
$$

where $t_{N}^{o}$ and $t_{T}^{o}$ represent the peak values of the nominal stress/traction when the deformation is either purely normal or tangential to the interface, respectively. The symbol \langle\rangle represents the Macaulay bracket which returns only positive values. It is used herein to indicate that a pure compressive deformation or stress state does not initiate damage.

The rate at which the material stiffness is degraded once the corresponding initiation criterion is reached is described by the damage evolution law. The overall damage in the material is represented by a scalar damage variable, $D$, which monotonically increases from 0 to 1 upon further loading after the initiation of damage. The stress components of the traction-separation model are affected by the damage according to

$$
\begin{aligned}
& t_{N} \\
& =\left\{\begin{array}{l}
(1-D) \bar{t}_{N}, \\
\bar{t}_{N} \geq 0, \\
\bar{t}_{N}, \\
\text { otherwise (No damage to compressive stiffness), }
\end{array}\right.
\end{aligned}
$$

$$
t_{T}=(1-D) \bar{t}_{T}
$$

where $\bar{t}_{N}$ and $\bar{t}_{T}$ are, respectively, the normal and shear stress components that are predicted by the elastic tractionseparation behavior for the current strains without damage.

In Abaqus, the damage evolution can be described based on the displacement at failure or based on the fracture energy dissipated as a result of the damage process. The damage softening can be linear, exponential, or in tabular form. Linear damage softening based on the failure displacement is used herein in which the damage evolution variable $D$ reduces to the following expression:

$$
D=\frac{\delta_{m}^{f}\left(\delta_{m}^{\max }-\delta_{m}^{o}\right)}{\delta_{m}^{\max }\left(\delta_{m}^{f}-\delta_{m}^{o}\right)},
$$

where $\delta_{m}=\sqrt{\delta_{N}^{2}+\delta_{T}^{2}}, \delta_{m}^{f}=$ resultant displacement at complete failure, $\delta_{m}^{o}=$ resultant displacement at damage initiation, and $\delta_{m}^{\max }=$ maximum value of the resultant displacement during loading.

In this work, the friction between the CNT and the cement matrix after debonding is ignored because the surface of the pristine CNT is very smooth. All stresses in the normal direction are ignored. Hence, the deformation is assumed to be purely tangential.
2.1.5. Interfacial Transition Zone (ITZ or Interphase). As previously noted, the interphase in fiber-reinforced composite is a transition region, which extends from nanometers to microns. The mechanical properties change from the bulk properties of the fiber to those of the matrix in the interphase. In carbon nanofiber-reinforced polymer composites, nanoindentation and AFM were used to determine the property gradient such as the reduced elastic modulus within the interphase. It is widely accepted that the interphase has a heterogeneous nature. However, no attempts were done to estimate the interphase thickness relative to the fiber diameter or fiber volume fraction within the polymer. Also, no specific distribution of the interphase elastic modulus was reported in the literature (i.e., linear distribution, nonuniform, heterogeneous, etc.). Studying the ITZ in the CNT-reinforced cementitious materials is not an easy task due to the brittle nature of the cement paste. Limited research work was reported in the literature. Hence, a parametric study was carried out to investigate the effect of the interphase volume fraction relative to the cement matrix assuming a uniform distribution around the CNT. Since the precise spatial variation in the interphase is not known, the distribution of the elastic modulus within the interphase varied. The following distributions have been considered: (1) a uniform distribution with a specific average elastic modulus value, (2) a nonuniform linear distribution (increasing or decreasing) assuming the interphase has the modulus of the matrix material at the interphase/matrix boundary and has a specified modulus value at the interphase/CNT boundary, and (3) stochastic elastic modulus values within the interphase which follow a normal distribution. The later distribution may be the most realistic one.

\section{Parametric Studies}

No effort has been put yet towards investigating the ITZ mechanical properties and width in the nanocomposite cement paste. The new techniques, which are used to investigate the properties of the ITZ in composites (such as nanoindentation and AFM), are not widely utilized in the nanocomposite cement paste due to the challenges associated with investigating this phase and/or locating the nanotubes in brittle material such as cement paste. On the other hand, from economical (time and cost) point of view, performing straightforward macro-microexperimental measurements on a number of samples of various particle sizes, types, shapes, volume fractions, and dispersions/distributions under different loading conditions is hardly a feasible task. However, at the present time, it is still not possible to perform atomistic or molecular dynamics simulations (MD) on realistic time scales and structures. Therefore, in this study, a four-phase axisymmetric model was developed to carry out a parametric study considering all possible ITZ volume fractions (widths) and elastic modulus distributions within the ITZ to explore the effect of those parameters on the overall elastic properties of the composite. The results of this study can be used as a guide for the experimental program that should be adopted to investigate the ITZ properties according to the degree of impact of each parameter on the overall behavior. 


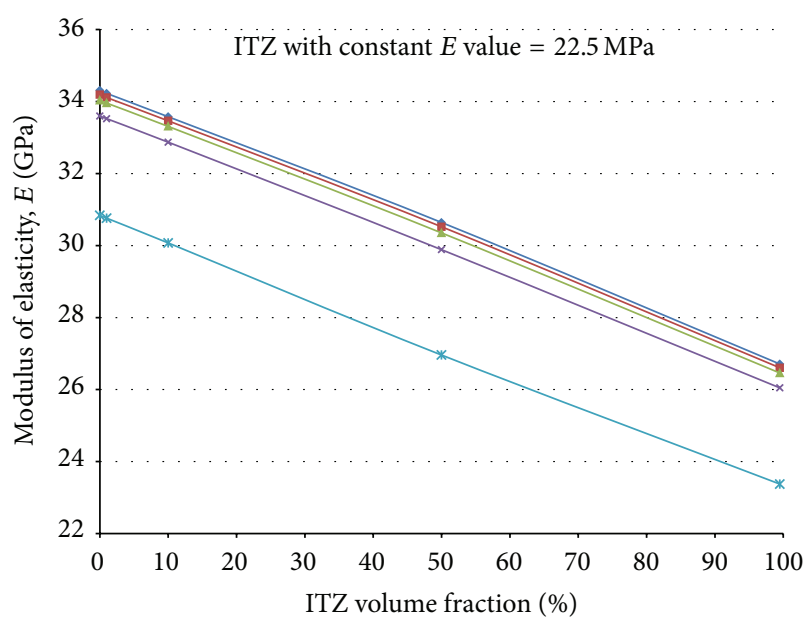

(a)

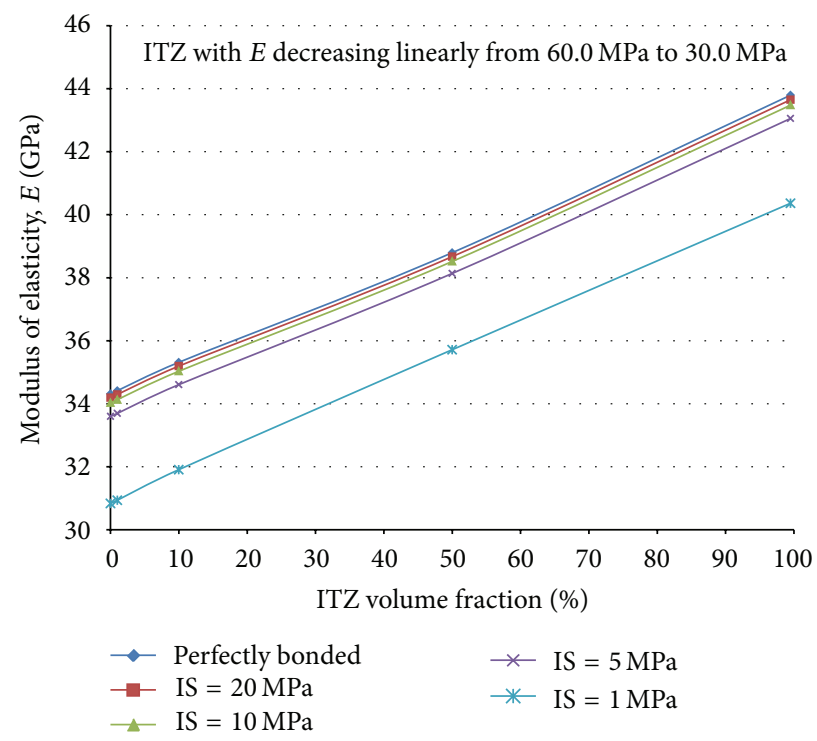

(c)

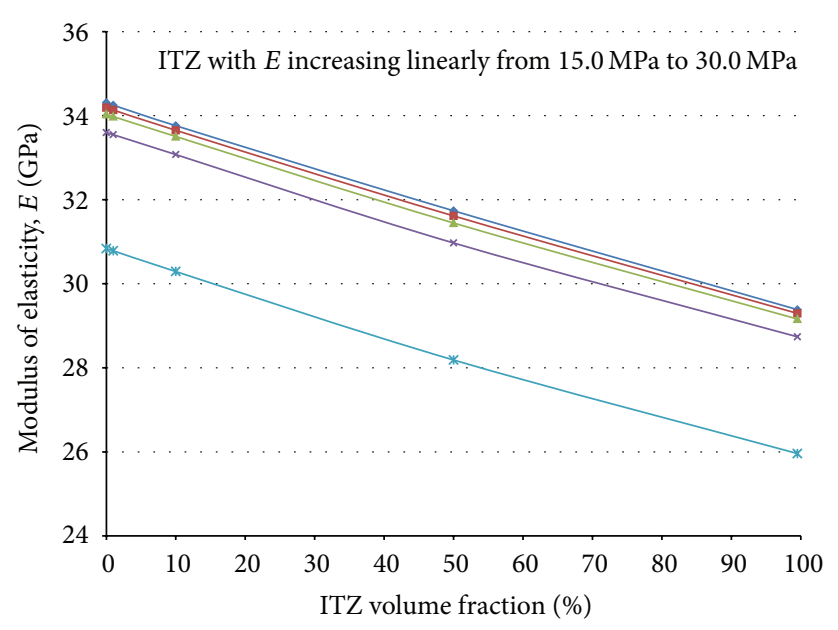

(b)

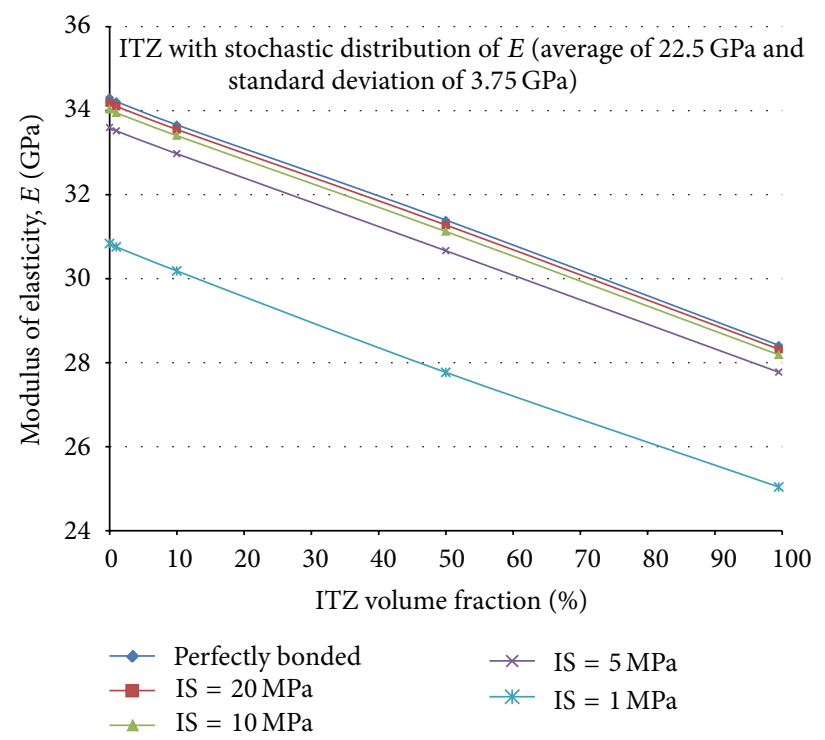

(d)

FIgURE 2: Average elastic modulus versus ITZ volume fraction: (a) uniform $E$ for ITZ, (b) linearly increasing $E$ within ITZ, (c) linearly decreasing $E$ within ITZ, and (d) stochastic distribution of $E$ within ITZ.

3.1. ITZ Volume Fraction. Four ITZ volume fractions were investigated, namely, $1.0 \%, 10.0 \%, 50.0 \%$, and $99.5 \%$ of the total matrix volume. The width of the ITZ was assumed to be uniform around the fiber as shown in Figure 2.

3.2. Distribution of Interphase Elastic Modulus. The following four assumptions for the distribution of the ITZ elastic modulus were investigated:

(1) A uniform distribution with an average elastic modulus value equal to $75 \%$ of that of the cement matrix; that is, $E_{I}=0.75 E_{C}=22.5 \mathrm{GPa}$.

(2) A nonuniform linear distribution with $E_{I}=E_{C}=$ $30.0 \mathrm{GPa}$ at the interphase/matrix boundary and $E_{I}=$ $0.5 E_{C}=15.0 \mathrm{GPa}$ at the interphase/CNT boundary (i.e., increasing when moving away from $\mathrm{CNT}$ ).
(3) Nonuniform linear distribution with $E_{I}=E_{C}=$ $30.0 \mathrm{GPa}$ at the interphase/matrix boundary and $E_{I}=$ $2 E_{C}=60.0 \mathrm{GPa}$ at the interphase/CNT boundary (i.e., decreasing when moving away from CNT).

(4) Stochastic normal distribution with an average elastic modulus value equal to $75 \%$ of that of the cement matrix $\left(E_{I \text { (avr.) }}=0.75 E_{C}=22.5 \mathrm{GPa}\right)$ and a 95\% confidence level that the elastic modulus values within ITZ are in the range of $0.5 E_{C}=15.0 \mathrm{GPa}$ and $E_{C}=30.0 \mathrm{GPa}$.

3.3. Interfacial Properties. As aforementioned, a limited number of attempts to investigate the interfacial properties in nanocomposite cementitious materials could be found in the literature. The interfacial shear strength values between the steel fiber-reinforced concrete (SFRC) and cement-based 
TABLE 2: Elastic modulus for different interfacial strengths and ITZ volume fractions (case 1: uniform ITZ elastic modulus = $22.5 \mathrm{GPa}$ ).

\begin{tabular}{|c|c|c|c|c|c|}
\hline \multirow{2}{*}{ Interfacial shear strength } & \multicolumn{5}{|c|}{ ITZ volume fraction (\%) } \\
\hline & 0 (no ITZ) & 1 & 10 & 50 & 99.5 \\
\hline Perfectly bonded & 34.312 & 34.226 & 33.578 & 30.641 & 26.709 \\
\hline$S=20 \mathrm{MPa}$ & 34.193 & 34.111 & 33.464 & 30.522 & 26.605 \\
\hline$S=10 \mathrm{MPa}$ & 34.033 & 33.956 & 33.309 & 30.351 & 26.46 \\
\hline$S=5 \mathrm{MPa}$ & 33.598 & 33.524 & 32.871 & 29.885 & 26.047 \\
\hline$S=1 \mathrm{MPa}$ & 30.836 & 30.76 & 30.073 & 26.959 & 23.375 \\
\hline
\end{tabular}

TABLE 3: Elastic modulus for different interfacial strengths and different ITZ volume fractions (case 2: increasing ITZ elastic modulus from 15.0 GPa to $30.0 \mathrm{GPa}$, average of $22.5 \mathrm{GPa}$ ).

\begin{tabular}{|c|c|c|c|c|c|}
\hline \multirow{2}{*}{ Interfacial shear strength } & \multicolumn{5}{|c|}{ ITZ volume fraction (\%) } \\
\hline & 0 (no ITZ) & 1 & 10 & 50 & 99.5 \\
\hline Perfectly bonded & 34.312 & 34.250 & 33.762 & 31.737 & 29.385 \\
\hline$S=20 \mathrm{MPa}$ & 34.193 & 34.135 & 33.652 & 31.615 & 29.295 \\
\hline$S=10 \mathrm{MPa}$ & 34.033 & 33.980 & 33.505 & 31.446 & 29.161 \\
\hline$S=5 \mathrm{MPa}$ & 33.598 & 33.548 & 33.075 & 30.971 & 28.738 \\
\hline$S=1 \mathrm{MPa}$ & 30.836 & 30.785 & 30.291 & 28.186 & 25.960 \\
\hline
\end{tabular}

matrices are in the range from 1.4 MPa to 9.6 $\mathrm{MPa}$ as reported by Naaman et al. [15]. Also, Chan and Andrawes [16, 17] reported an effective shear strength value of 6.5 MPa between CNTs and the cement matrix by calibrating the numerical model using three-point bending test results.

In this parametric study, interfacial shear strength $\mathrm{IS}_{T}$ values of $1,5,10$, and $20 \mathrm{MPa}$ were investigated for $0.5 \% \mathrm{CNT}$ volume fraction and $110 \mathrm{CNT}$ aspect ratio. The interfacial initial stiffness and allowable slip before failure were fixed at $1 \times 10^{-8} \mathrm{~N} / \mathrm{nm}^{3}$ and $0.25 \mathrm{~nm}$, respectively.

\section{Analysis, Results, and Discussion}

The effect of the ITZ volume fraction and the mechanical properties of the interface (modeled as cohesive surface) on the longitudinal elastic modulus were studied. The effect of the friction between the CNT and cement matrix after debonding was ignored herein. The purely tangential deformation was also not considered herein. The CNT volume fraction and the aspect ratio were fixed to $0.50 \%$ and 110 , respectively. The interface and interphase properties were previously discussed. The computations were performed using a constant displacement rate until the axial strain reached a strain value of 0.0005 . The effect of each individual parameter and the interaction of those effects are discussed in the following sections.

4.1. Effect of Interfacial Transition Zone Volume Fraction. Tables 2, 3, 4, and 5 show the predicted composite elastic modulus using different interfacial shear strengths and ITZ volume fractions. The results were obtained using the following assumptions about the ITZ elastic modulus variation: (1) constant, (2) linearly increasing, (3) linearly decreasing, and (4) stochastic. It is worth noting that in these models, the ITZ was assumed to be perfectly bonded to the cement matrix and the cohesive surface was assumed to be between the CNT and
ITZ. The ITZ was also assumed to be uniformly distributed around the CNT, and hence it had a constant thickness that was computed based on its volume fraction. This thickness could be measured using AFM and nanoindentation techniques.

Figures 2(a), 2(b), 2(c), and 2(d) show the variation of the composite elastic modulus with the ITZ volume fraction for different distributions of the elastic modulus within the ITZ.

The results show that assuming an interfacial shear strength of $20 \mathrm{MPa}$ gives elastic modulus values, which are very close to those of the perfectly bonded case regardless of the distribution of the elastic modulus within the ITZ. Hence, a shear strength value of $20 \mathrm{MPa}$ at the CNT/cement interface has a considerable effect on the mechanical properties of the composite.

Figures 2(a), 2(b), and 2(d) show that for the same interface strength, the elastic modulus of the composite decreases with an increase in the volume fraction (thickness) of the ITZ. This is logical because the ITZ was assumed to be weaker than the cement matrix. Then, by increasing the width of this "weak chain," the overall elastic modulus of the composite will be lower. It could be also noted in Tables 2, 3, and 5 that, generally, if the volume fraction of the "weaker" ITZ is considered more than $50 \%$ of the cement matrix volume, the elastic modulus of the composite will be lower than the elastic modulus of the matrix. Hence, it is important to investigate the mechanical properties and width of this layer in order to study the effect of the fibers on the matrix properties.

In Figure 2(c), the ITZ elastic modulus was assumed to be two times larger than that of the matrix at the interface and linearly decreasing until its value reaches that of the matrix at the interphase/matrix boundary. The average elastic modulus of the ITZ in this case is $45 \mathrm{GPa}$, which is more than that of the cement paste. Hence, the ITZ can be considered as a "strong chain" for nanocomposite polymers. Increasing the width of 
TABLE 4: Elastic modulus for different interfacial strengths and different ITZ volume fractions (case 3: decreasing ITZ elastic modulus from 60.0 GPa to $30.0 \mathrm{GPa}$, average of $45.0 \mathrm{GPa}$ ).

\begin{tabular}{|c|c|c|c|c|c|}
\hline \multirow{2}{*}{ Interfacial shear strength } & \multicolumn{5}{|c|}{ ITZ volume fraction (\%) } \\
\hline & 0 (no ITZ) & 1 & 10 & 50 & 99.5 \\
\hline Perfectly bonded & 34.312 & 34.413 & 35.316 & 38.796 & 43.795 \\
\hline$S=20 \mathrm{MPa}$ & 34.193 & 34.293 & 35.195 & 38.671 & 43.649 \\
\hline$S=10 \mathrm{MPa}$ & 34.033 & 34.129 & 35.032 & 38.517 & 43.478 \\
\hline$S=5 \mathrm{MPa}$ & 33.598 & 33.693 & 34.607 & 38.137 & 43.055 \\
\hline$S=1 \mathrm{MPa}$ & 30.836 & 30.937 & 31.909 & 35.716 & 40.365 \\
\hline
\end{tabular}

TABLE 5: Elastic modulus for different interfacial strengths and different ITZ volume fractions (case 4: stochastic elastic modulus within ITZ with average of $22.5 \mathrm{GPa}$ and standard deviation of $3.75 \mathrm{GPa}$ ).

\begin{tabular}{|c|c|c|c|c|c|}
\hline \multirow{2}{*}{ Interfacial shear strength } & \multicolumn{5}{|c|}{ ITZ volume fraction (\%) } \\
\hline & 0 (no ITZ) & 1 & 10 & 50 & 99.5 \\
\hline Perfectly bonded & 34.312 & 34.22 & 33.663 & 31.396 & 28.415 \\
\hline$S=20 \mathrm{MPa}$ & 34.193 & 34.106 & 33.554 & 31.279 & 28.323 \\
\hline$S=10 \mathrm{MPa}$ & 34.033 & 33.952 & 33.406 & 31.124 & 28.189 \\
\hline$S=5 \mathrm{MPa}$ & 33.598 & 33.521 & 32.975 & 30.666 & 27.775 \\
\hline$S=1 \mathrm{MPa}$ & 30.836 & 30.758 & 30.185 & 27.77 & 25.041 \\
\hline
\end{tabular}

the ITZ increases the overall elastic modulus of the composite as shown in Figure 2(c).

As noted previously, the cracking and plasticity of the matrix including the ITZ were not taken into account herein because the work focuses on the elastic response of the composite. This may cause further reduction in the composite elastic modulus when "cracked" in the elastic range.

\subsection{Effect of the Distribution of the Elastic Modulus within} the ITZ. Figures 3(a), 3(b), 3(c), 3(d), and 3(e) show the variation of the composite elastic modulus with the ITZ volume fraction for each interface strength assuming different distributions of the ITZ elastic modulus.

Figure 3 shows that increasing the width of the ITZ has almost the same impact on the composite elastic modulus regardless of the interface strength. Moreover, the effect of the elastic modulus distribution within the ITZ becomes more significant as the width of the ITZ increases. This may lead to question whether there is a relationship between the interface strength, the CNT diameter, or volume fraction and the ITZ volume fraction (thickness). This can be the subject of a future experimental work to study the effect of the thickness of the ITZ on the CNT-reinforced cement paste and its relationship to the other parameters. However, it can be also noted that assuming a uniform distribution within the ITZ (case 1) gives elastic modulus values less than those obtained when assuming a linear increase in the $E$ value within the ITZ (case 2) or stochastic distribution (case 4). It is also worth noting that the three cases have the same average elastic modulus value $(22.5 \mathrm{GPa})$. The difference is higher for wider ITZ.

Let us first investigate the results of the perfectly bonded case and compare them to the upper and lower limits of the theory of mixtures for composite materials. It is worth noting that the theory of mixtures considers that the CNT and the matrix are springs acting on parallel and on series. Let us consider the case where the ITZ volume fraction was assumed equal to $99.5 \%$. This case corresponds to the entire matrix being interphase with a uniform average $E$ value of $22.5 \mathrm{GPa}$. The upper and lower bounds of the theory of mixtures, which were computed using the equations, $E_{\mathrm{Upper}}=f_{\mathrm{CNT}} E_{\mathrm{CNT}}+$ $f_{\mathrm{C}} E_{\mathrm{C}}$ and $E_{\text {Lower }}=E_{\mathrm{CNT}} E_{\mathrm{C}} / f_{\mathrm{C}} E_{\mathrm{CNT}}+f_{\mathrm{CNT}} E_{\mathrm{C}}$, were found to be equal to $27.388 \mathrm{GPa}$ and $22.611 \mathrm{GPa}$, respectively. However, a more realistic assumption is to consider the CNT and matrix to be acting in parallel over the length of the CNT and then this composite acting in series with the cement matrix in the part above the CNT. In the region over the length of the CNT, the CNT volume fraction is equal to 0.00682. In this region, the effective elastic modulus is equal to $29.165 \mathrm{GPa}$ (in parallel action). This region, comprising $\mathrm{CNT}$ and the matrix along CNT length, has a volume fraction of 0.733 acting in series with another region of plain cement matrix which has 0.267 volume fraction above CNT to give average composite elastic modulus of $27.027 \mathrm{GPa}$. This is very close to the value of $26.709 \mathrm{GPa}$ shown in Table 2 and lies within the upper and lower limits of the theory of mixtures for composite materials.

Let us consider the case where the ITZ volume fraction was assumed to be $1 \%$ with a uniform average $E$ value of $22.5 \mathrm{GPa}$. Applying the above-mentioned assumption, 0.338 CNT volume fraction will act in parallel with the ITZ and this composite (volume fraction $=0.0202$ ) is in turn acting in parallel with the cement matrix over the length of the ITZ to give an average elastic modulus value of $36.514 \mathrm{GPa}$. Then this region, which has a volume fraction of 0.733 , is acting in series with a 0.267 volume fraction of cement matrix above the CNT. The elastic modulus of the part of the cement matrix, including the ITZ and cement paste, is calculated the same way and found be to be equal to $29.997 \mathrm{GPa}$. Then, the average composite elastic modulus is $34.512 \mathrm{GPa}$ which is very fairly close to the value shown in Table 2 (i.e., $34.226 \mathrm{GPa}$ ). 


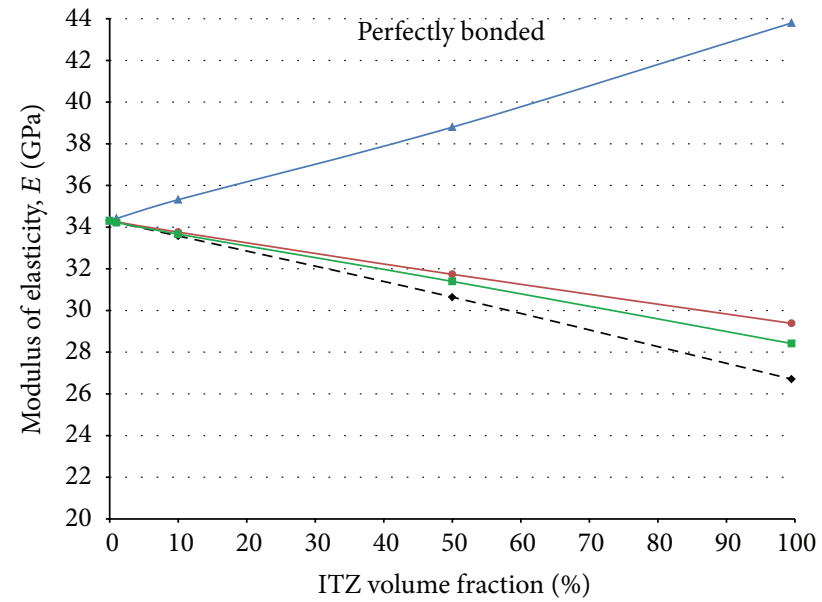

(a)

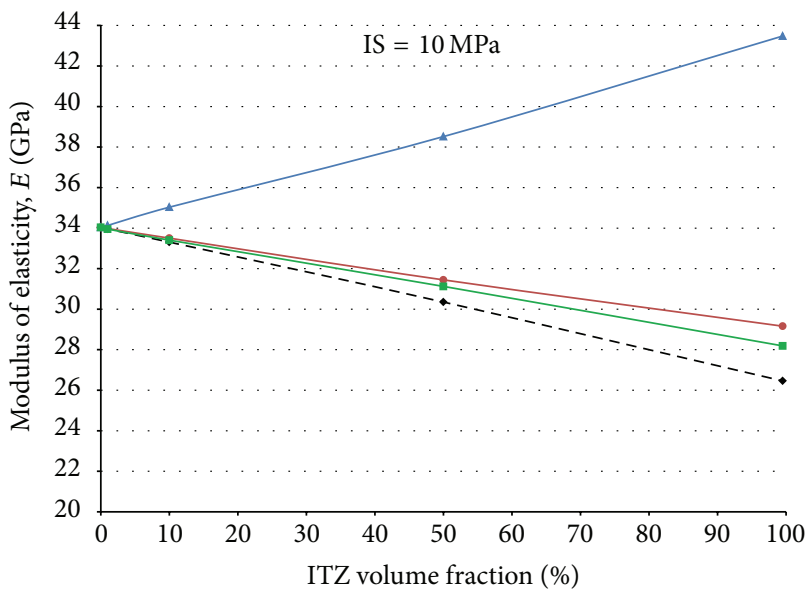

(c)

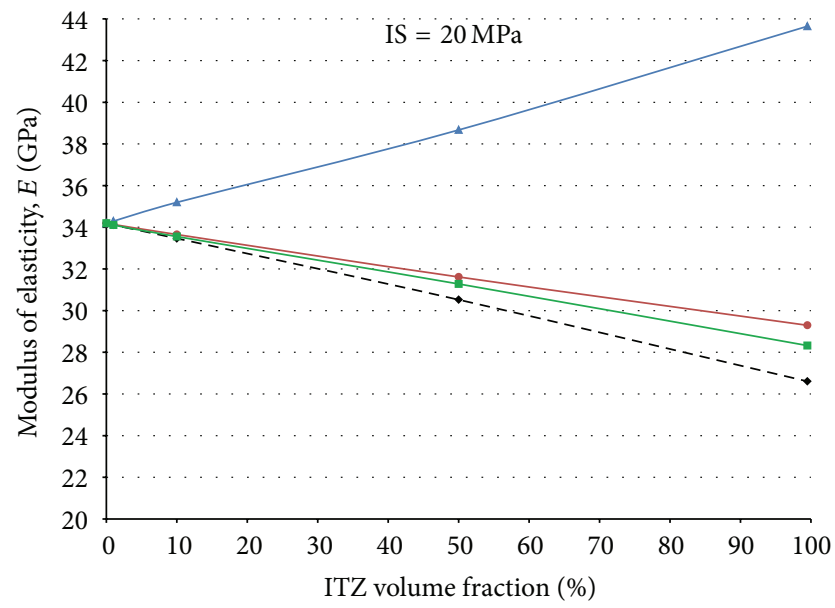

(b)

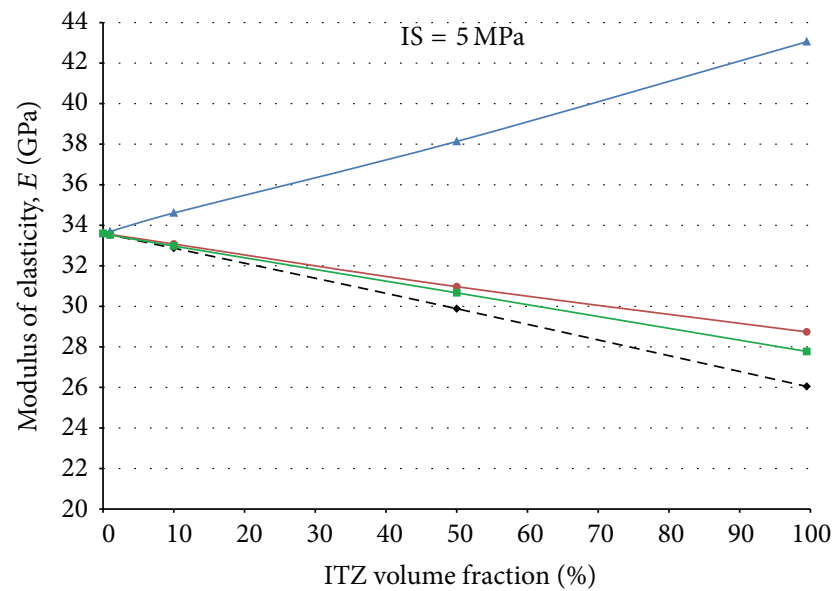

(d)

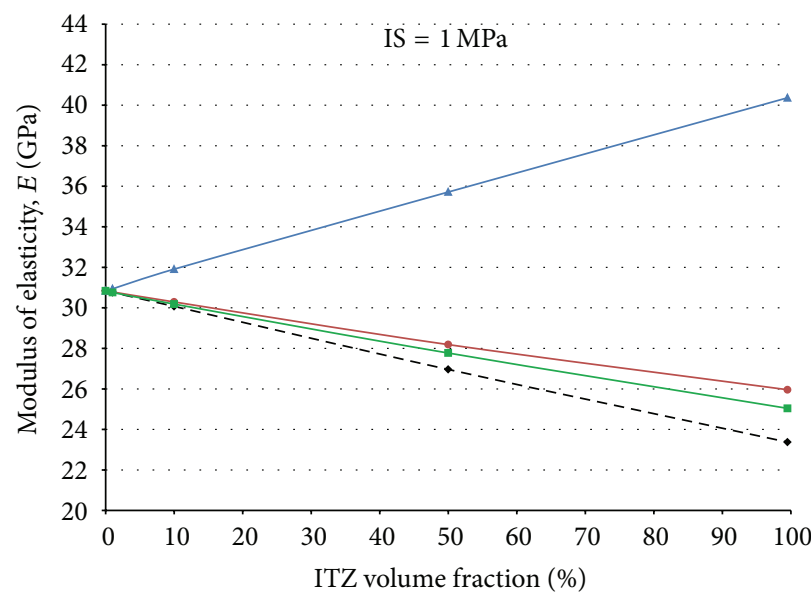

- - Uniform $E=22.5 \mathrm{GPa}$

- $E$ increasing linearly from $15.0 \mathrm{GPa}$ to $30.0 \mathrm{GPa}$ (average of $22.5 \mathrm{GPa}$ )

$\rightarrow E$ decreasing linearly from $60.0 \mathrm{GPa}$ to $30.0 \mathrm{GPa}$

$\rightarrow$ Stochastic $E$ distribution with average of $22.5 \mathrm{GPa}$ and standard deviation of $3.75 \mathrm{GPa}$

(e)

FIGURE 3: Plots of the average elastic modulus versus ITZ volume fraction: (a) perfectly bonded interface, (b) interfacial strength $=20 \mathrm{MPa}$, (c) interfacial strength $=10 \mathrm{MPa}$, (d) interfacial strength $=5 \mathrm{MPa}$, and (e) interfacial strength $=1 \mathrm{MPa}$. 
Applying the same calculation procedure to the case where the elastic modulus is increasing linearly within the ITZ, the composite elastic modulus was found to be equal to $34.535 \mathrm{GPa}$ which is very close to the value shown in Table 3 (i.e., $34.25 \mathrm{GPa}$ ). The composite elastic modulus is slightly larger than the one obtained in the case of uniform distribution.

As noted above, the assumption of the spatial distribution of the mechanical properties within the ITZ is essential and has a considerable effect on the elastic response of the composite. Hence, nanoindentation needs to be used to study the mechanical properties within this layer in order to be able to have a valid computational finite element model with real assumptions.

Moreover, the use of stochastic normally distributed $E$ values within the ITZ (with an average value of $22.5 \mathrm{GPa}$ and 95\% confidence level in which all $E$ values within the ITZ lie between 15 and $30 \mathrm{GPa}$ ) generated overall composite elastic modulus values between those obtained when assuming uniform and linearly increasing elastic modulus with the same average value. The assumption of stochastic normal distribution may give results which are more accurate and closer to the reality.

4.3. Effect of the Location of the Cohesive Surface. The cohesive surface was assumed to be between the CNT and the ITZ in all previous models. However, it was observed from the pull-out test carried out for CNTs embedded in the cement matrix that part of the hydration components were attached to the surface of pulled-out CNTs. Hence, the insertion of a cohesive surface at the boundary between the ITZ and the cement paste needs to be investigated.

Table 6 compares the predicted composite elastic modulus for $50 \%$ ITZ volume fraction using different interfacial strengths and assuming different distributions of the elastic modulus within the ITZ.

The results summarized in Table 6 show that the location of the cohesive surface significantly affect the elastic modulus of the composite. Regardless of the distribution of the ITZ elastic modulus, the elastic modulus values obtained when considering the cohesive surface between the interphase and the cement matrix were lower than those obtained when assuming the cohesive surface at the interface between the CNT and the interphase. According to the geometry of the four-phase model shown in Figure 1, the length of the boundary between the CNT and the ITZ is less than the one between ITZ and cement matrix. Hence, the smaller the cohesive surface area is, the higher the composite elastic modulus is.

\section{Conclusions}

The paper studied the effect of ITZ and interfacial properties on the elastic properties of the CNT-reinforced cement paste using a four-phase axisymmetric model. The following conclusions could be drawn.

(i) For the same ITZ volume fraction and the same distribution of the mechanical properties within the ITZ, increasing the interface strength increases the elastic modulus of the nanocomposite until it reaches the maximum value, which corresponds to the perfectly bonded case.

(ii) The results also show that assuming an interface strength value of $20 \mathrm{MPa}$ generates elastic modulus values which are very close to the perfectly bonded case. Hence, achieving this shear strength value at the $\mathrm{CNT} /$ cement interface has a considerable effect on the mechanical properties of the composite.

(iii) Assuming that the ITZ is weaker than the cement paste, the elastic modulus of the composite decreases by increasing the volume fraction (thickness) of the ITZ for a specific interface strength (regardless of the distribution of the elastic modulus within the ITZ). On the contrary, increasing the width of the ITZ increases the overall elastic modulus of the composite if the ITZ is assumed to be stronger than the cement matrix (elastic modulus is linearly increasing within the ITZ).

(iv) Generally, considering more than $50 \%$ as volume fraction of a "weaker" ITZ results in a composite elastic modulus less than the matrix elastic modulus. Hence, it is important to investigate the mechanical properties and width of this layer in order to study the effect of the CNTs on the matrix properties.

(v) The increasing or decreasing trends of the composite elastic modulus due to an increase of the width of the ITZ is almost the same for all interface strengths.

(vi) The effect of the distribution of the elastic modulus within the ITZ becomes more significant as the width of the ITZ increases.

(vii) Assuming a uniform distribution within the ITZ gives elastic modulus values less than those obtained when assuming a linearly increasing trend within the ITZ. The difference is larger for wider ITZs.

(viii) The assumption of normally distributed $E$ values within the ITZ gives composite elastic modulus values that lie between those resulting from assuming uniform and linearly increasing elastic modulus with the same average value.

(ix) The location of the cohesive surface significantly affects the elastic modulus of the composite.

Future experimental work may be directed towards exploring the elastic properties of the nanocomposite cement paste using the static compression test. The thickness of the ITZ in the CNT-reinforced cement paste and its relation to other parameters may be also investigated using the AFM technology, for example. Moreover, nanoindentation may be carried out to study the local nanomechanical properties of the nanocomposite cement paste and within the ITZ in order to be able to have valid computational finite elements model with real assumptions. 


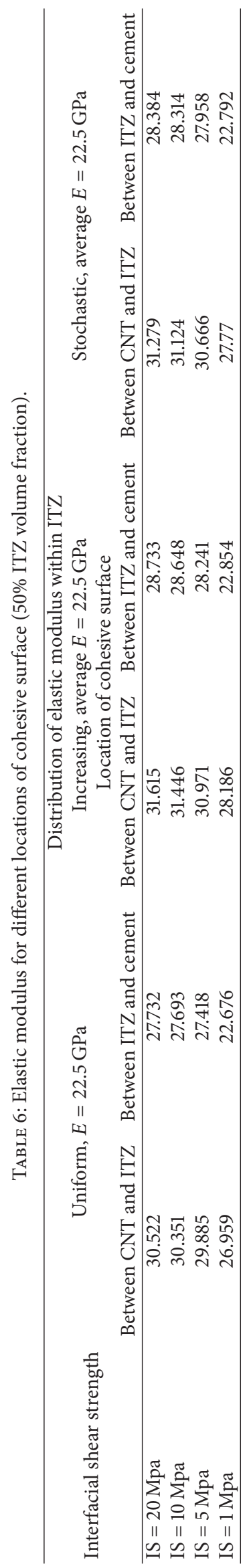




\section{Disclaimer}

The statements made herein are solely the responsibility of the authors.

\section{Conflict of Interests}

The authors declare that there is no conflict of interests regarding the publication of this paper.

\section{Acknowledgment}

This work was made possible by a National Priority Research Program award (NPRP 4-1142-2-440) from the Qatar National Research Fund (a member of The Qatar Foundation).

\section{References}

[1] E. T. Thostenson, Z. Ren, and T.-W. Chou, "Advances in the science and technology of carbon nanotubes and their composites: a review," Composites Science and Technology, vol. 61, no. 13, pp. 1899-1912, 2001.

[2] P. G. Collins and P. Avouris, "Nanotubes for electronics," Scientific American, vol. 283, no. 6, pp. 62-69, 2000.

[3] S. Bellucci, F. Micciulla, S. Bistarelli et al., "Biological effects of functionalized multi-walled carbon nanotubes on human cancer and normal cell lines," Jacobs Journal of Nanomedicine and Nanotechnology, vol. 1, no. 1, pp. 1-5, 2014.

[4] A. A. Ensafi, H. Karimi-Maleh, S. Mallakpour, and M. Hatami, "Simultaneous determination of $\mathrm{N}$-acetylcysteine and acetaminophen by voltammetric method using N-(3,4-dihydroxyphenethyl)-3,5-dinitrobenzamide modified multiwall carbon nanotubes paste electrode," Sensors and Actuators B: Chemical, vol. 155, no. 2, pp. 464-472, 2011.

[5] A. A. Ensafi, H. Karimi-Maleh, S. Mallakpour, and B. Rezaei, "Highly sensitive voltammetric sensor based on catecholderivative-multiwall carbon nanotubes for the catalytic determination of captopril in patient human urine samples," Colloids and Surfaces B: Biointerfaces, vol. 87, no. 2, pp. 480-488, 2011.

[6] T. Tavana, M. A. Khalilzadeh, H. Karimi-Maleh, A. A. Ensafi, H. Beitollahi, and D. Zareyee, "Sensitive voltammetric determination of epinephrine in the presence of acetaminophen at a novel ionic liquid modified carbon nanotubes paste electrode," Journal of Molecular Liquids, vol. 168, pp. 69-74, 2012.

[7] A. Mokhtari, H. Karimi-Maleh, A. A. Ensafi, and H. Beitollahi, "Application of modified multiwall carbon nanotubes paste electrode for simultaneous voltammetric determination of morphine and diclofenac in biological and pharmaceutical samples," Sensors and Actuators, B: Chemical, vol. 169, pp. 96-105, 2012.

[8] R. Moradi, S. A. Sebt, H. Karimi-Maleh et al., "Synthesis and application of FePt/CNTs nanocomposite as a sensor and novel amide ligand as a mediator for simultaneous determination of glutathione, nicotinamide adenine dinucleotide and tryptophan," Physical Chemistry Chemical Physics, vol. 15, no. 16, pp. 5888-5897, 2013.

[9] M. Najafi, M. A. Khalilzadeh, and H. Karimi-Maleh, "A new strategy for determination of bisphenol $\mathrm{A}$ in the presence of Sudan i using a $\mathrm{ZnO} / \mathrm{CNT}$ s/ionic liquid paste electrode in food samples," Food Chemistry, vol. 158, pp. 125-131, 2014.
[10] O. Breuer and U. Sundararaj, "Big returns from small fibers: a review of polymer/carbon nanotube composites," Polymer Composites, vol. 25, no. 6, pp. 630-645, 2004.

[11] J. N. Coleman, M. Cadek, R. Blake et al., "High-performance nanotube-reinforced plastics: understanding the mechanism of strength increase," Advanced Functional Materials, vol. 14, no. 8, pp. 791-798, 2004.

[12] S. C. Tjong, "Structural and mechanical properties of polymer nanocomposites," Materials Science and Engineering R, vol. 53, no. 3-4, pp. 73-197, 2006.

[13] M. Moniruzzaman and K. I. Winey, "Polymer nanocomposites containing carbon nanotubes," Macromolecules, vol. 39, no. 16, pp. 5194-5205, 2006.

[14] N. Chandra, "Cohesive zone approach to multiscale modeling of nanotube reinforced composites," Final Report, Florida A\&M University, 2007.

[15] A. E. Naaman, G. G. Namur, J. M. Alwan, and H. S. Najm, "Fiber pullout and bond slip. II: Experimental validation," Journal of Structural Engineering, vol. 117, no. 9, pp. 2791-2800, 1991.

[16] L. Y. Chan and B. Andrawes, "Characterization of the uncertainties in the constitutive behavior of carbon nanotube/cement composites," Science and Technology of Advanced Materials, vol. 10, no. 4, Article ID 045007, 2009.

[17] L. Chan and B. Andrawes, "Numerical modeling of flexural enhancement in carbon nanotube/cement composite," in Proceedings of the Structures Congress, pp. 1-8, May 2009.

[18] S. S. Nair, S. Wang, and D. C. Hurley, "Nanoscale characterization of natural fibers and their composites using contactresonance force microscopy," Composites Part A: Applied Science and Manufacturing, vol. 41, no. 5, pp. 624-631, 2010.

[19] G. Li, Y. Zhao, and S.-S. Pang, "Four-phase sphere modeling of effective bulk modulus of concrete," Cement and Concrete Research, vol. 29, no. 6, pp. 839-845, 1999.

[20] Z. Sun, E. J. Garboczi, and S. P. Shah, "Modeling the elastic properties of concrete composites: experiment, differential effective medium theory, and numerical simulation," Cement and Concrete Composites, vol. 29, no. 1, pp. 22-38, 2007.

[21] M. P. Lutz, P. J. M. Monteiro, and R. W. Zimmerman, "Inhomogeneous interfacial transition zone model for the bulk modulus of mortar," Cement and Concrete Research, vol. 27, no. 7, pp. 11131122, 1997.

[22] W. Zhu and P. J. M. Bartos, "Application of depth-sensing microindentation testing to study of interfacial transition zone in reinforced concrete," Cement and Concrete Research, vol. 30, no. 8, pp. 1299-1304, 2000.

[23] P. Mondal, S. P. Shah, and L. D. Marks, "Nanomechanical properties of interfacial transition zone in concrete," in Nanotechnology in Construction 3, pp. 315-320, Springer, Berlin, Germany, 2009.

[24] W. Zhu, M. Sonebi, and P. J. M. Bartos, "Bond and interfacial properties of reinforcement in self-compacting concrete," Materials and Structures, vol. 37, no. 271, pp. 442-448, 2004.

[25] J. G. Williams, M. E. Donnellan, M. R. James, and W. L. Morris, "Properties of the interphase in organic matrix composites," Materials Science and Engineering A, vol. 126, no. 1-2, pp. 305312, 1990.

[26] M. R. Vanlandingham, S. H. Mcknight, G. R. Palmese et al., "Nanoscale indentation of polymer systems using the atomic force microscope," The Journal of Adhesion, vol. 64, no. 1-4, pp. 31-59, 1997. 
[27] M. Munz, H. Sturm, E. Schulz, and G. Hinrichsen, "The scanning force microscope as a tool for the detection of local mechanical properties within the interphase of fibre reinforced polymers," Composites Part A: Applied Science and Manufacturing, vol. 29, no. 9-10, pp. 1251-1259, 1998.

[28] K. Mai, E. Mäder, and M. Mühle, "Interphase characterization in composites with new non-destructive methods," Composites Part A: Applied Science and Manufacturing, vol. 29, no. 9-10, pp. 1111-1119, 1998.

[29] T. A. Bogetti, T. Wang, M. R. Vanlandingham, and J. W. Gillespie Jr., "Characterization of nanoscale property variations in polymer composite systems: 2. Numerical modeling," Composites Part A: Applied Science and Manufacturing, vol. 30, no. 1, pp. 85-94, 1999.

[30] T. D. Downing, R. Kumar, W. M. Cross, L. Kjerengtroen, and J. J. Kellar, "Determining the interphase thickness and properties in polymer matrix composites using phase imaging atomic force microscopy and nanoindentation," Journal of Adhesion Science and Technology, vol. 14, no. 14, pp. 1801-1812, 2000.

[31] A. Hodzic, Z. H. Stachurski, and J. K. Kim, "Nano-indentation of polymer-glass interfaces. Part I. Experimental and mechanical analysis," Polymer, vol. 41, no. 18, pp. 6895-6905, 2000.

[32] R. Kumar, W. M. Cross, L. Kjerengtroen, and J. J. Kellar, "Fiber bias in nanoindentation of polymer matrix composites," Composite Interfaces, vol. 11, no. 5-6, pp. 431-440, 2004.

[33] F. Li, J. G. Williams, B. S. Altan, I. Miskioglu, and R. L. Whipple, "Studies of the interphase in epoxy-aluminum joints using nano-indentation and atomic force microscopy," Journal of Adhesion Science and Technology, vol. 16, no. 7, pp. 935-949, 2002.

[34] S.-H. Lee, S. Wang, G. M. Pharr, and H. Xu, "Evaluation of interphase properties in a cellulose fiber-reinforced polypropylene composite by nanoindentation and finite element analysis," Composites Part A: Applied Science and Manufacturing, vol. 38, no. 6, pp. 1517-1524, 2007.

[35] S. H. Lee, S. Wang, T. Endo, and N. H. Kim, "Visualization of interfacial zones in lyocell fiber-reinforced polypropylene composite by AFM contrast imaging based on phase and thermal conductivity measurements," Holzforschung, vol. 63, no. 2, pp. 240-247, 2009.

[36] Y. Gu, M. Li, J. Wang, and Z. Zhang, "Characterization of the interphase in carbon fiber/polymer composites using a nanoscale dynamic mechanical imaging technique," Carbon, vol. 48, no. 11, pp. 3229-3235, 2010.

[37] A. Pakzad, J. Simonsen, and R. S. Yassar, "Gradient of nanomechanical properties in the interphase of cellulose nanocrystal composites," Composites Science and Technology, vol. 72, no. 2, pp. 314-319, 2012.

[38] A. Needleman, T. L. Borders, L. C. Brinson, V. M. Flores, and L. S. Schadler, "Effect of an interphase region on debonding of a CNT reinforced polymer composite," Composites Science and Technology, vol. 70, no. 15, pp. 2207-2215, 2010.

[39] H. R. Pakravan, M. Jamshidi, and M. Latifi, "Adhesion of polypropylene fiber to cement matrix," Journal of Adhesion Science and Technology, vol. 26, no. 10-11, pp. 1383-1393, 2012.

[40] X. H. Wang, S. Jacobsen, J. Y. He, Z. L. Zhang, S. F. Lee, and H. L. Lein, "Application of nanoindentation testing to study of the interfacial transition zone in steel fiber reinforced mortar," Cement and Concrete Research, vol. 39, no. 8, pp. 701-715, 2009.
[41] W. R. L. Da Silva, J. Němeček, and P. Štemberk, "Methodology for nanoindentation-assisted prediction of macroscale elastic properties of high performance cementitious composites," Cement and Concrete Composites, vol. 45, pp. 57-68, 2014.

[42] A. G. Abu Taqa, R. K. Abu Al-Rub, A. Senouci, N. AlNuaimi, and K. B. Hani, "The effect of fiber geometry and interfacial properties on the elastic properties of cementitious nanocomposite material," Journal of Nanomaterials, vol. 2015, Article ID 283579, 14 pages, 2015.

[43] K. I. Tserpes and P. Papanikos, "Finite element modeling of single-walled carbon nanotubes," Composites Part B: Engineering, vol. 36, no. 5, pp. 468-477, 2005.

[44] M. N. Nahas and M. Abd-Rabou, "Finite element modeling of carbon nanotubes," International Journal of Mechanical \& Mechanics Engineering, vol. 10, no. 3, pp. 19-24, 2010.

[45] V. M. Harik, T. S. Gates, and M. P. Nemeth, "Applicability of the continuum-shell theories to the mechanics of carbon nanotubes," ICASE Report no. 2002-7, 2002.

[46] V. M. Harik, "Mechanics of carbon nanotubes: applicability of the continuum-beam models," Computational Materials Science, vol. 24, no. 3, pp. 328-342, 2002.

[47] G. M. Odegard, T. S. Gates, L. M. Nicholson, and K. E. Wise, "Equivalent-continuum modeling of nano-structured materials," Composites Science and Technology, vol. 62, no. 14, pp. 18691880,2002 

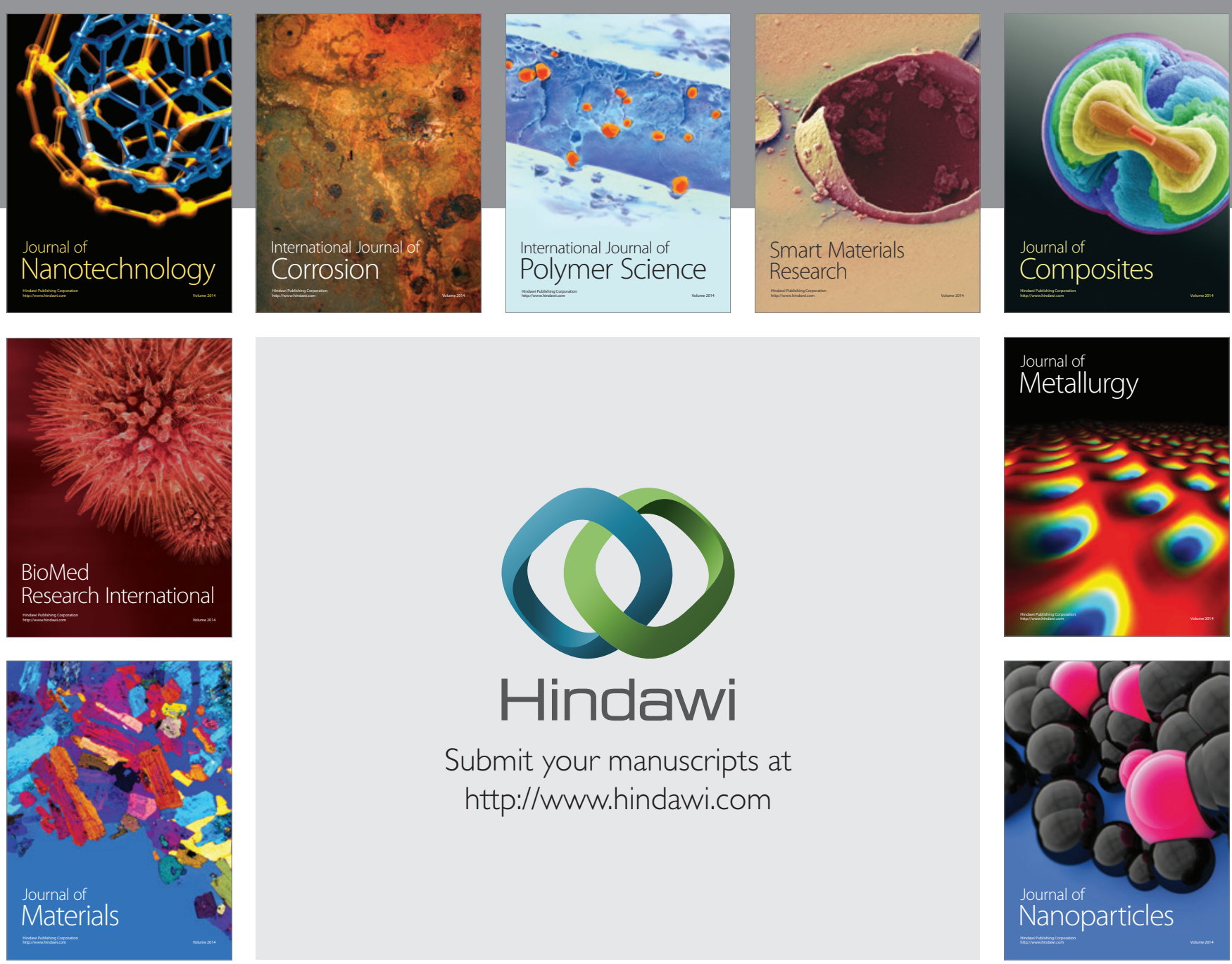

Submit your manuscripts at http://www.hindawi.com
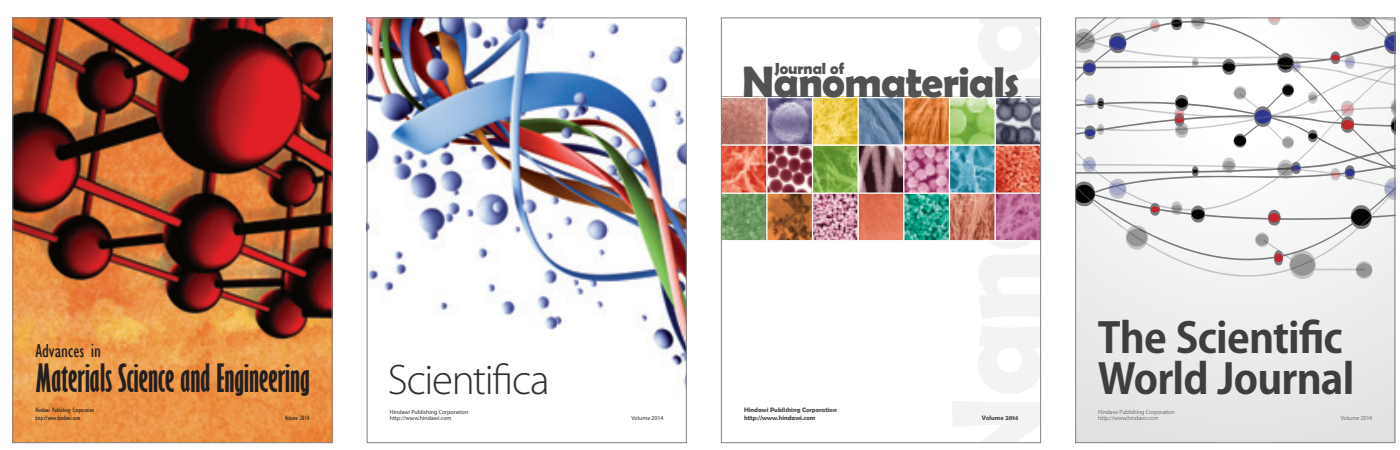

\section{The Scientific World Journal}
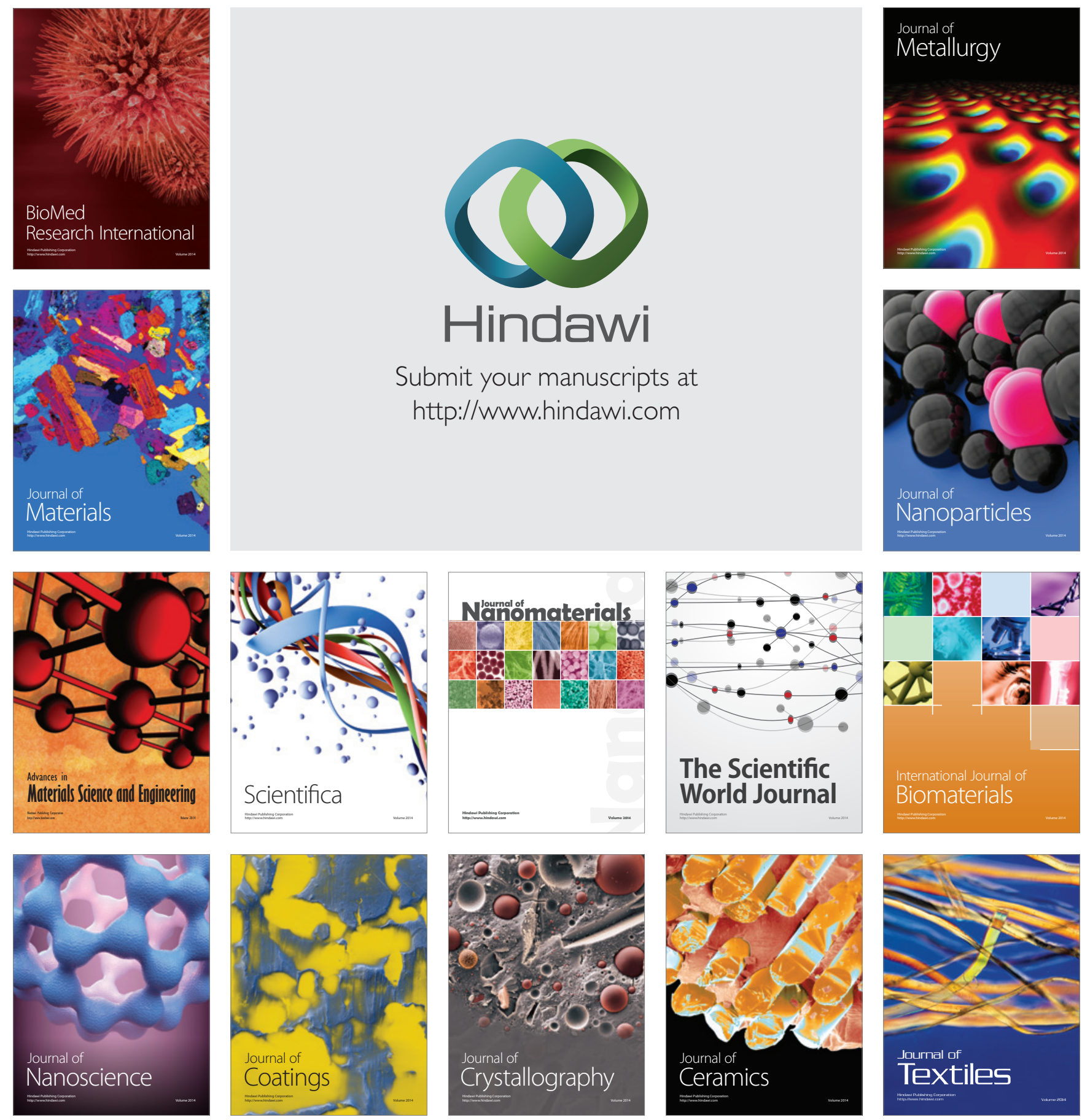